\title{
Axitinib/Pembrolizumab Regimen
}

National Cancer Institute

\section{Source}

National Cancer Institute. Axitinib/Pembrolizumab Regimen. NCI Thesaurus. Code

C162220.

A regimen consisting of axitinib and pembrolizumab that can be used for the treatment of advanced renal cell carcinoma (RCC). 